\title{
Entre as ruas e as instituições: os protestos e o impeachment de Dilma Rousseff
}

\author{
Luciana Tatagiba \\ Professora Livre-Docente do Departamento de Ciência Política, da \\ Universidade Estadual de Campinas (Unicamp). Coordenadora do Núcleo \\ de Pesquisa em Participação, Movimentos Sociais e Ação Coletiva, NEPAC/ \\ UNICAMP \\ Rua Mata Atlântica, 180, Bosque de Barão Geraldo, Campinas, São Paulo, \\ Brasil, 13082-755 \\ tatagiba@g.unicamp.br
}

\section{Resumo}

O artigo analisa a campanha pelo impeachment de Dilma Rousseff, buscando compreender as condições para a emergência e sucesso dos protestos de direita. Como foi possível que organizações desconhecidas tivessem êxito em mobilizar uma base social sem tradição de protestos, em um cenário de confronto político até então dominado pela esquerda? O artigo propõe que a resposta está na forma como se combinou política institucional e mobilização social nessa conjuntura, a partir da laboriosa construção do antipetismo, ou mesmo do ódio ao PT.

\section{Palavras-chave}

protestos - direita - confronto político - antipetismo 


\title{
Entre les rues et les institutions : Les protestations et la campagne de destituion de Dilma Rousseff
}

\section{Résumé}

L'article analyse la campagne de destitution de Dilma Rousseff, cherchant à comprendre les conditions pour l'émergence et le succès des manifestations de droite. Comment était-il possible que des organisations inconnues aient réussi à mobiliser une base sociale qui n'avait pas tradition de protestation, dans un scénario de confrontation politique jusqu'alors dominé par la gauche? La réponse proposée par l'article réside dans la manière dont la politique institutionnelle et la mobilisation sociale ont été combinées dans cette conjoncture, à partir de la construction laborieuse de l'antipétisme, ou de la haine envers le PT.

\section{Mots-clés}

protestation - droite - confrontation politique - antipétisme

\section{Between the Streets and the Institutions: the Protests and the Impeachment of Dilma Rousseff}

\begin{abstract}
The article examines the campaign to impeach Dilma Rousseff in an effort to comprehend the conditions underpinning the emergence and success of the right-wing protests. How was it that unknown organizations succeeded in mobilizing a social base with no tradition of protest, in a context of political contention that was until then controlled by the left? The article suggests that the answer lies in the way that the institutional politics and the social mobilization combined together from the laborious construction of the anti-PT drive, or the hatred of PT.
\end{abstract}

\section{Keywords}

protests - right-wing - political contention - anti-PT 


\section{Introdução}

Em 19 de março de 1964, na antessala do golpe militar, a "Marcha da Família com Deus pela Liberdade" levava cerca de 500 mil pessoas ao centro de São Paulo para protestar contra as Reformas de Base, propostas pelo então presidente João Goulart (Dreifuss 1981: 297), e em defesa da legalidade e da democracia. A Marcha, assim como as outras manifestações que a antecederam, produziu forte impacto na opinião pública abrindo novas oportunidades políticas para os opositores do regime. Quando os militares assumiram o poder, as direitas recolheram-se aos seus nichos de atividade e não produziram novas manifestações públicas e massivas de apoio ao regime.

Na década seguinte, a resistência à ditadura, combinada com a luta por melhores condições de vida nas cidades, gerou um dos mais importantes ciclos de protestos da história política brasileira, entre 1978 e 1988, tendo como protagonistas os setores sindical e popular (Sader 1988, Doimo 1992). Desde então, a esquerda tem dominado o cenário do confronto político no Brasil, contando com organizações com forte capacidade de recrutamento e mobilização, como a Central Única dos Trabalhadores (CUT), o Movimento dos Trabalhadores Rurais Sem Terra (MST), a União Nacional dos Estudantes (UNE) e o próprio Partido dos Trabalhadores (PT), uma sorte de partido-movimento (Meneguello 1989). É possível dizer que nas décadas seguintes o repertório da ação coletiva no Brasil foi uma repetição, adaptada às circunstâncias, das inovações geradas nesse vigoroso ciclo de mobilização.

Esse padrão de participação sócio-política sofreu importantes mudanças no ciclo de protestos de Junho de $2013^{1}$. Sob um clima geral de insatisfação em relação às instituições da democracia representativa e descrença nas organizações políticas tradicionais, os protestos de junho recolocaram as ruas como lugar da luta política, rompendo com um padrão de institucionalização das demandas que marcou o período democrático. Os protestos produziram efeitos imediatos sobre o regime político dos governos petistas, enfraquecendo sua base de apoio social e parlamentar.

As direitas brasileiras souberam ler o "espírito de junho" e renovaram o seu repertório de ação, até então restrito à lógica eleitoral e ao lobby, para incluir o confronto político. Em 15 de março de 2015, um milhão e 350 mil manifestantes tomaram as ruas das cidades brasileiras para protestar contra o governo de Dilma Rousseff. Um ano depois, novo protesto levava 3 milhões de pessoas para as ruas para exigir o impeachment da Presidente e prisão para o

1 O ciclo de protesto de Junho de 2013 suscitou, e ainda suscita, diferentes interpretações. Para uma aproximação com esse debate conferir: Mische e Alonso, 2013; Judensnaider, E. et al 2013, Antunes, 2013; Singer, 2013; Tatagiba, 2014; Bringel, 2017. 
ex-presidente Lula, um feito inédito para os padrões de mobilização no Brasil. Os protestos foram transmitidos ao vivo em cadeia aberta de televisão e tiveram forte impacto na opinião pública.

Os protestos mobilizaram, principalmente, as classes médias e altas que responderam à convocação de organizações sem lastro social ou institucional, criadas para intervir diretamente na conjuntura crítica. $\mathrm{O}$ alvo dos desafiadores não era apenas o governo petista, mas a esquerda partidária e sindical e a cultura de esquerda de uma forma mais ampla. Essa disposição fica evidente nas palavras de ordem dos protestos: "O Brasil não será uma outra Venezuela", "Minha bandeira nunca será vermelha", "Quero meu país de volta" ou ainda, em tom de confronto "Vai para Cuba!". Um dos organizadores do livro "Direitas Volver! O retorno da direita e o ciclo político brasileiro"2, Sebastião Velasco e Cruz, destaca de forma enfática a novidade da conjuntura, "Aconteceu, finalmente: a direita no Brasil mostrou sua cara. $\mathrm{E}$ o fez ruidosamente, mal contida em seu entusiasmo, vencidas as barreiras que a inibiram por tanto tempo, condenando-a a uma existência sombria, discreta e envergonhada" (Cruz 2015:3).

A campanha pelo impeachment foi construída em diferentes arenas institucionais e extra institucionais. A rua foi apenas mais uma dessas arenas, mas teve implicações relevantes para a escalada do conflito e seu desfecho. A voz das ruas emprestou legitimidade a atores que buscavam contestar os resultados das urnas e propor, ato contínuo à vitória de Rousseff no segundo turno da eleição presidencial, o seu impedimento.

Como foi possível que organizações desconhecidas tivessem êxito em mobilizar uma base social sem tradição de protestos de rua e sustentar uma campanha que, em exatos vinte e dois meses, destituiu uma presidenta democraticamente eleita, alterando por completo o panorama político institucional do país? O que explica a força numérica e simbólica dos protestos convocados pela direita, em um cenário de confronto político até então dominado pela esquerda? Essas são as questões que buscarei tratar neste texto.

O ponto de partida deste artigo é que a explicação se encontra no nexo entre política contestatória e institucional, na direção proposta pela abordagem do confronto político (Mcadam, Tarrow e Tilly 2001, Tilly 2006). Ao se deslocar do foco restrito nas mobilizações ou nos atores sociais tomados isoladamente, a abordagem toma como objeto de investigação as interações contenciosas entre a diversidade de atores e arenas que tomam parte do confronto. Na ótica da mútua influência, movimentos sociais e protestos são definidos como agentes de mudança que buscam afetar ao mesmo tempo em que são afetados pela política institucional.

2 Essa foi uma das primeiras publicações que tomaram as novas direitas como objeto. 
Seguindo por essa via, o artigo sustenta que o surgimento e o êxito dos protestos pelo impeachment devem-se à conformação de uma base social antipetista, laboriosamente construída a partir de uma complexa relação entre dinâmicas de mobilização e dinâmicas eleitorais ou, tomando de empréstimo as formulações de Mcadam e Tarrow (2011), entre confronto político e "confronto eleitoral". A partir de 2014, o antipetismo como fenômeno sócio-político, encontrou um terreno fértil para o seu desenvolvimento com o início das investigações da Polícia Federal, com a Operação Lava Jato, destinada a investigar desvios de recursos públicos e lavagem de dinheiro.

Para desenvolver o argumento, o texto está dividido em três partes. Na primeira, tomo as mobilizações à direita como objeto, buscando descrever suas principais características, a partir de algumas variáveis já consagradas na sociologia dos movimentos sociais, como infraestrutura organizacional, demandas e repertórios. Na segunda parte, exploro a forma como representação política e mobilização social se combinaram a partir da ativação do antipetismo, um poderoso gatilho emocional para o protesto. Na terceira parte, detenho-me na cronologia do conflito para evidenciar as conexões entre o ativismo do judiciário e o timing e modelagem do protesto. A análise aqui desenvolvida está baseada no inédito banco de dados de protestos no Brasil, produzido no âmbito da Pesquisa "Protestos no Brasil 1998-2016", coordenado pela autora em parceria com a Prof ${ }^{\mathrm{a}} \mathrm{Dr}^{\mathrm{a}}$ Andreia Galvão (DCP/Unicamp $)^{3}$; nas pesquisas de opinião realizadas por institutos e grupos de pesquisa durante os protestos ${ }^{4}$; além da literatura sobre os protestos das novas direitas e o antipetismo que apesar de ainda incipientes já oferecem alguns pontos de partida para a análise.

\section{1 \\ As direitas em movimento e os protestos pró-impeachment}

São grandes os desafios metodológicos e éticos envolvidos no estudo das mobilizações à direita. No caso brasileiro, a essas dificuldades se soma certo desinteresse pelo objeto que persistiu até que a onda conservadora e de direita cobrasse atenção da academia. Essa temporalidade responde pela natureza

3 A construção do banco de dados segue a metodologia de Análise de Eventos de Protestos (AEP), e recupera as informações publicadas pelo jornal de circulação nacional, Folha de São Paulo, sobre eventos de protestos e greves realizados em todo o território nacional e cobrindo uma diversidade de temas. Foi realizada cobertura diária dos jornais e sua sistematização segue os parâmetros definidos pela AEP. Para uma análise global do banco remeto a Galvão e Tatagiba 2018.

4 Datafolha 2015a e 2015b, Fundação Perseu Abramo 2016, Telles 2015, Index e Amostra 2015, Solano e Ortellado 2015, Ortelado, Solano e Nader 2016. 
mais exploratória dos estudos produzidos, esse artigo incluso. Um desafio adicional na pesquisa tem a ver com a dificuldade em definir o próprio objeto.

Ainda no final dos anos de 1980, Flávio Pierucci (1987) alertava que para compreender as novas direitas era preciso partir do reconhecimento de sua diversidade interna. Partindo da metáfora espacial, ele lembra que as variações não se reduzem à distribuição ao longo do continuum, da extremidade até o centro do eixo, com a extrema direita, a direita e o centro-direita. A árvore da direta, ele afirma, é "uma árvore composta por diferentes raízes", sendo nossa tarefa compreender "sua genealogia" e as diferentes concepções que abriga. Elas atuam em camadas sobrepostas, que vão se desenrolando em ritmos diferentes ao longo do tempo e a partir de trincheiras variadas, que operam com relativa autonomia programática e organizativa.

Ciente dessa diversidade e dos riscos e desafios implicados nessa definição, quando me refiro aqui aos protestos de direita, o faço em um sentido estrito. Defino como protestos de direita: a) protestos convocados por organizações autodeclaradas de direita e/ou conservadoras e/ou que encontram nessas redes as bases infra estruturais do protesto; b) e/ou protestos cujas demandas voltam-se à contestação dos valores, políticas e propostas orientados pelos pressupostos da justiça social e da igualdade humana. Sua localização à direita resulta, portanto, de uma posição relacional contra a esquerda, no âmbito estrito dessa metáfora espacial.

Entre janeiro de 2011 e dezembro de 2016, foram registrados 1358 eventos de protestos, em todo o país. Desse total, $10 \%$ foram classificados como protestos de direita, seguindo a definição oferecida acima. A evolução dos protestos de direita ao longo do período mostra forte concentração em 2015 (28\% do total) e 2016 (representando 30\% do total). Mas, em 2013 há um primeiro pico (aumento de quase cem por cento em relação ao ano anterior), o que reforça a tese de que o ciclo de mobilização de 2013 ofereceu oportunidades políticas para novos atores, tanto à esquerda quanto à direita.

Setenta por cento dos protestos de direita tiveram como demanda o combate à corrupção, a defesa do impeachment de Dilma Rousseff e/ou a prisão de Lula. Os demais temas, marginais em relação a esse polo central, giraram em torno da questão da ordem e da segurança e da "defesa dos valores da família" dirigido principalmente contra políticas de promoção dos direitos sexuais e reprodutivos. Embora no discurso das organizações a pauta econômica fosse um tema importante, ela não encontrou eco nos protestos, a não ser em demandas mais pontuais e episódicas associadas à redução dos impostos.

A campanha pelo impeachment se destacou por sua força numérica e simbólica. No que se refere ao número de manifestantes e capilaridade territorial, a campanha produziu cinco grandes mobilizações nacionais, quatro delas em 


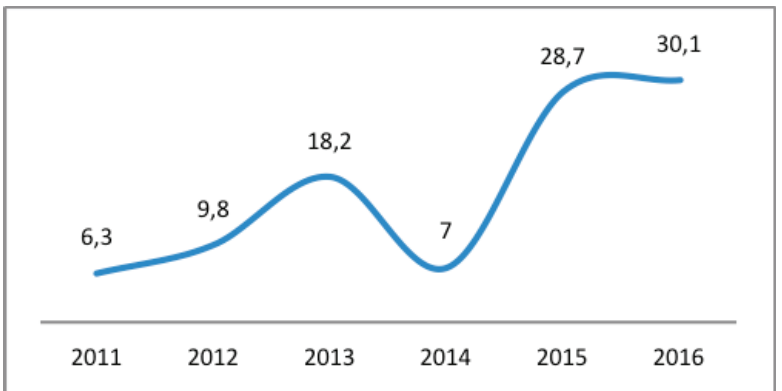

GRÁfICO 1 Evolução anual dos protestos de direita (\%). FONTE: BANCO DE DADOS DE PROTESTOS NO BRASIL (NEPAC/CEMARX).

2015 e uma no começo de 2016. A primeira, realizada em 15 de março de 2015, foi a maior manifestação desde o movimento pelas Diretas Já, em 1984, com um milhão e 700 mil pessoas. A última mobilização massiva, em 13 de março de 2016, reuniu três milhões de pessoas em todo o país. Os dados acerca da capilaridade do protesto mostram que a onda da direita se espalhou por todos os estados brasileiros, em cidades de diferentes portes populacionais ${ }^{5}$. O grande palco do impeachment foi a Avenida Paulista, colocando o Estado de São Paulo no epicentro dos protestos. Segundo o Instituto Datafolha, no protesto de março de 2016, a Avenida Paulista foi tomada por 500 mil pessoas, a maior mobilização já registrada na história da cidade.

As performances confrontacionais das direitas incluíram o repertório básico do movimento social moderno, com predominância de manifestações, atos, carreatas, marchas, bloqueio de vias e ocupação de espaço público. A marca estética dos protestos foi o uso dos símbolos nacionais, como o verde e amarelo da bandeira brasileira que ornou várias peças publicitárias e "vestiu" os manifestantes, como já ocorrera em campanhas anteriores, como as Direitas Já, em 1984, e o Fora Collor, em 1992 (Mische e Alonso 2017, Tatagiba 2014). Também se destacaram referências misóginas e sexistas contra a Presidente ao longo de toda a campanha (Rubim e Argolo 2016). As principais inovações das direitas foram o "panelaço", ato de bater panelas em janelas ou sacadas dos edifícios que geralmente acompanharam os pronunciamentos nacionais da Presidente Dilma Rousseff, e um novo padrão de relação com as forças de

5 As cinco cidades que mais abrigaram esses protestos foram, por ordem: São Paulo, Brasília, Rio de Janeiro, Curitiba e Belo Horizonte. Destaque para a cidade de Curitiba que não tem tradição em protestos de rua, mas se destaca por ser a sede da Operação Lava Jato, sobre a qual falarei nos próximos itens. 
segurança, marcados por sinais recíprocos de cordialidade e reconhecimento. Destaca-se ainda a eficiente utilização das redes sociais de comunicação para gerar mobilização, repercutir os protestos e recrutar novos aderentes.

As organizações que se destacaram na convocação dos protestos foram o Vem pra Rua, o Movimento Brasil Livre (MBL) e, com menor participação, o Revoltados on Line, ao lado de uma miríade de pequenos grupos surgidos após a intensificação do conflito, para organizar a mobilização localmente ${ }^{6}$. $\mathrm{O}$ Revoltados Online foi criado em 2000, por um ex-pastor evangélico e dentre as três é a que possui maior proximidade com a extrema-direita, assumindo na campanha pelo impeachment um discurso altamente radicalizado com incitação à violência física e defesa da intervenção militar, demandas que já haviam apresentado nos protestos de 2013 (Dias 2017:54).

O M BL foi criado em 2013, para intervir diretamente nos ciclos de mobilização pelo impeachment. O MBL surgiu associado aos Estudantes pela Liberdade, a filial brasileira do Students for Liberty, que tem como objetivo formar jovens liberais a partir de uma atuação centrada nas universidades (Gobbi 2016). Suas lideranças são jovens e um dos objetivos declarados da organização é "rejuvenescer" o discurso da direita no Brasil. Dentre os valores defendidos pelo grupo está a diminuição do papel do Estado na economia, a defesa das privatizações, a crítica às políticas sociais do governo petista, em especial o programa Bolsa Família e as políticas de reparação, como as cotas raciais nas universidades, e a defesa da redução da maioridade penal. O MBL é a organização que teve mais capacidade de combinar a ação nas ruas, com um investimento nas instituições, principalmente a partir do lançamento de candidaturas. Por fim, o Vem pra Rua, que é a mais nova das quatro organizações, foi fundada em 2014 para atuar diretamente na campanha eleitoral em defesa do candidato do PSDB, Aécio Neves. Suas lideranças são empresários com conexões com as elites econômicas e políticas de São Paulo. Em sua página na internet afirmam que defendem a "ética na política" e a luta contra a corrupção, ao lado da liberdade econômica e redução dos impostos (Dias 2017).

Essas organizações, no curso dos eventos e ao sabor das circunstâncias, combinaram a defesa de políticas de austeridade com pautas conservadoras no plano da moral. Sem recursos políticos expressivos, contaram com o apoio financeiro e logístico de organizações poderosas como a Federação das Indústrias do Estado de São Paulo (FIESP), a mídia hegemônica, principalmente as organizações Globo, as redes religiosas evangélicas, a Maçonaria

6 Sobre o perfil e projetos políticos das organizações envolvidas com a convocação dos protestos, ver Dias 2017, Gobbi 2016, Tatagiba, Trindade e Teixeira 2015. 
(Viegas 2015, Calgaro 2015), e centrais sindicais, como a Força Sindical e trabalhadores autônomos, como os caminhoneiros.

A participação dos setores empresariais na campanha pró-impeachment, principalmente articulados em torno da FIESP, destacou-se nas ruas a partir de setembro 2015, com a campanha "Eu não vou pagar o pato", que levou para a frente de sua sede na Avenida Paulista um pato amarelo de 12 metros de altura que representava a luta contra o aumento da carga tributária e pelo impeachment. Sobre o uso do pato como símbolo da campanha, explica Paulo Skaf dirigente da entidade: "O pato é aquele símbolo do bem para acabar com o mal.É uma figura alegre, simpática e que, de uma forma respeitosa mostra uma indignação"7. A campanha sugeria que não caberia aos cidadãos arcar com os custos decorrentes da corrupção. Ao lado das panelas e do boneco com a imagem do presidente Lula vestido de presidiário (nomeado "Pixuleco"), o "Pato da Fiesp" virou um dos principais símbolos do impeachment.

Outra rede importante para veiculação das mensagens antipetistas foi o movimento neopenteconstal, que utilizou uma de suas principais estratégias de mobilização, a Marcha para Jesus, para atacar a corrupção e "defender o Brasil". No dia 7 de junho 2014, acontecia em São Paulo a $22^{\mathrm{a}}$ Marcha para Jesus, com público total estimado pela PM em 250 mil manifestantes. O tema da Marcha foi "Conquistando para Cristo" e o objetivo era afirmar "o valor do patriotismo". Já na $23^{\text {a }}$ Marcha para Jesus, ocorrida em 4 de junho 2015 em São Paulo, no auge da campanha pelo impeachment, 340 mil participantes, segundo a PM, pediam "faxina ética" e "fim da corrupção" (FSP, 05/06/2015, A5). A narrativa neopentecostal da guerra contra o mal se encaixava perfeitamente com o espírito geral do antipetismo.

No que se refere ao perfil dos manifestantes, pesquisa realizada na grande manifestação de 15 de março de 2015 (Datafolha 2015a) na cidade de São Paulo, informa que $63 \%$ dos participantes eram do sexo masculino, com idade média de 40 anos, $76 \%$ com ensino superior (a média da cidade de São Paulo é $28 \%$ ), $69 \%$ se declararam brancos, e $41 \%$ possuem renda familiar acima de 10 salários mínimos (percentual na cidade de São Paulo é de 9\%). Destaque para a presença de empresários, $14 \%$ (contra $2 \%$ na cidade de São Paulo). Dados sobre simpatia e adesão partidária indicam que $94 \%$ não têm preferência partidária e que $82 \%$ dos presentes votaram em Aécio Neves, PSDB, no segundo turno das eleições (na cidade de São Paulo, Neves obteve 64\% dos votos). $91 \%$ dos participantes afirmaram não ter qualquer tipo de ligação com os grupos que

7 "Pato é símbolo de 'bem contra o mal", Não vou pagar o pato, consultado em 4 de Junho 2018, http://www.naovoupagaropato.com.br/deu-na-midia/pato-e-simbolo-de-bemcontra-o-mal/. 
convocaram os protestos, sendo o Facebook a principal fonte de recrutamento para os atos. Quanto ao posicionamento político, $85 \%$ afirmam que a democracia é sempre a melhor forma de governo e a maioria se localiza entre o centro e a direita. Esse perfil não apresentou alteração significativa nos protestos e sondagens posteriores (ver nota 5). O que as pesquisas de opinião confirmam é que os jovens e os trabalhadores não qualificados se mantiveram à margem do confronto, seja para defender o impeachment, seja para assegurar a continuidade do mandato da Presidente (Fundação Perseu Abramo 2016).

\section{Mobilização social e representação política na construção do antipetismo}

O antipetismo ofereceu a energia para o protesto, transformando insatisfações difusas em engajamento ativo com uma causa. $\mathrm{O}$ antipetismo tem uma dupla face: por um lado, é um fenômeno político-eleitoral que integra o que se convencionou chamar de negative partisanship, a rejeição exclusiva a um partido; por outro lado, é um fenômeno sócio-político que se expressa no ódio ao PT. O antipetismo evidencia as interações contenciosas das quais a mobilização se nutre, nesse caso em particular evidencia o nexo entre mudanças nos processos de representação política, imaginários sociais e a emergência dos protestos.

Como fenômeno político-eleitoral o antipetismo define-se por uma identidade partidária negativa, ou negative partisanship (Zucco e Samuels 2015), que embora beba na fonte do antipartidarismo apresenta características específicas. $\mathrm{O}$ antipartidarismo - a rejeição generalizada aos partidos enquanto organização política - é um fenômeno multifacetado que tem se destacado nos protestos em escala global, principalmente a partir de 2011, o Brasil incluso ${ }^{8}$. Já no caso da identidade partidária negativa a rejeição é direcionada a partidos específicos e tem forte poder de predição em relação ao comportamento do eleitor (Paiva, Krause e Lameirão 2016, Ribeiro, Carrerão e Borba 2016).

É comum na literatura, a referência ao PT como o partido mais amado e mais odiado do país, uma característica que o acompanha desde a sua fundação em 1980 (Amaral 2010, Keck 1992, Meneguello 1989). Mas, o que os estudos mostram é que a partir de 2002 houve um aumento significativo no percentual de eleitores antipetistas.

8 Resultados das pesquisas do Estudo Eleitoral Brasileiro (ESEB) mostram que mais da metade dos brasileiros não se sentem representados pelos partidos políticos, e que essa percepção vem crescendo ao longo dos últimos anos, atingindo 71,9\% em 2014 (Paiva, Krause e Lameirão 2016: 647). 
TABELA 1 Evolução de eleitores antipetistas (2002-2014)

(Percentual de respondentes)

\begin{tabular}{ll}
\hline Ano & $\%$ \\
\hline 2002 & 28 \\
2006 & 39 \\
2010 & 28 \\
2014 & 40 \\
\hline
\end{tabular}

Fonte: Adaptação da tabela em Ribeiro, Carrerão e Borba (2016: 619). Os autores tomaram como indicador de antipetismo as avaliações negativas (notas de o a 3) feitas pelos eleitores em relação ao PT.

Essas alterações vieram acompanhada de mudanças em relação à base de apoio do Partido, com maior aproximação dos setores populares e distanciamento das classes médias, como vários estudos têm indicado 9 :

Até 2002, o partido obtinha melhores chances entre os mais jovens, os mais escolarizados, os pertencentes à população economicamente ativa $(P E A)$, na região Sul e nas capitais e regiões metropolitanas. Na eleição de 2006, essas chances invertem-se e o partido passa a obter melhores resultados entre os mais velhos, os menos escolarizados, os que estão fora da $P E A$, fora da região Sul e fora das capitais e regiões metropolitanas. Isso significa que ocorreu uma transformação profunda na base de apoio socioeconômico do partido quando este se tornou governo.

MARTINS JR. 2009: 90

No que se refere à base social do antipetismo, os estudos apontam para um perfil muito semelhante ao encontrado nos protestos pró-impeachment,

O eleitor antipetista é predominantemente de cor branca, possui maior escolaridade e está em número superior ao dos demais eleitores nos estratos de maior renda familiar mensal, de camadas sociais mais elevadas e entre os empregadores. $\mathrm{O}$ antipetismo é um fenômeno, majoritariamente, da região Sudeste, principalmente paulista. Apesar de serem a

9 As análises de Singer sobre o lulismo também reforçam esse deslocamento das bases eleitorais do PT (Singer 2012). 
região e o estado mais populosos do Brasil, mesmo assim o antipetismo tem maior peso nessa região do que ela própria em relação ao restante do Brasil.

PAIVA, Krause e Lameirão 2016: 653

Os estudos também sugerem que o aumento do antipetismo está relacionado aos escândalos de corrupção: Mensalão em 2006, quando o percentual de eleitores antipetistas passa de $28 \%$ para $39 \%$; e Lava Jato, em 2014, quando o percentual salta de $28 \%$ para $40 \%$ (Paiva, Krause e Lameirão, 2016, Ribeiro, Carrerão e Borba 2016, Singer 2012). Combinado à Operação Lava Jato, o crescimento do antipetismo em 2014 também se beneficiou da corrida presidencial, a mais polarizada desde 1989, com mais uma edição da disputa PT versus PSDB.É interessante perceber nesse ponto a ligação entre a política eleitoral e os processos de mobilização e desmobilização, como analisado em McAdam e Tarrow (2011). No nosso caso específico, o "confronto eleitoral"10 foi importante para o surgimento dos movimentos de direita, ao acionar dois processos principais: a "mobilização eleitoral pró ativa e reativa" (ibid.). Os autores afirmam que a mobilização eleitoral proativa ocorre quando "grupos de movimentos tornam-se mais ativos no contexto de uma campanha eleitoral" (ibid:: 27). No nosso caso, a campanha eleitoral não apenas gerou maior atividade de grupos de direita, como também gerou a criação de organizações que mais tarde protagonizariam os protestos. Já a "mobilização eleitoral reativa" está relacionada a uma "escalada de protestos na sequência de uma eleição contestada" (ibid.: 28), o que no caso brasileiro deu o start da campanha pelo impeachment. Menos de 24 horas depois de ser derrotado no segundo turno por Dilma Rousseff, o candidato oposicionista Aécio Neves (PSDB) conclamou a população às ruas contra o governo recém-eleito, acusando fraude eleitoral. Foi a primeira vez, desde o restabelecimento da democracia, que um candidato derrotado não reconhece o resultado das urnas. Esse ato catalisou as forças oposicionistas e direcionou para os protestos as insatisfações até então difusas contra o governo petista.

Como fenômeno sociopolítico, o que define o antipetismo não é apenas rejeição ao PT, mas o ódio ao PT, um sentimento com forte potencial mobilizador. Foi o ódio ao PT, performado nos confrontos públicos, que permitiu aos manifestantes, a maioria deles sem experiência prévia em protestos, construir-secomo coletividades. Esseenvolvimento afetivo coma causa conferiu

10 Por confronto eleitoral os autores entendem "o conjunto das relações entre movimentos e eleições que definem tanto a dinâmica dos movimentos, quanto o resultado das eleições" (McAdam e Tarrow 2011: 24). 
contornos particulares ao protesto, com imagens de manifestantes mordendo ou queimando bandeiras do PT, ou levando cartazes com imagens dos expresidentes decapitados ou enforcados. A agressividade foi alimentada por um uso muito particular das redes sociais (Dias 2017, Gobbi 2016) e teve o poder de pervadir outras esferas da vida cotidiana, como as relações familiares e de amizade. Essa disposição cognitiva e emocional teve importantes implicações para o recrutamento e para as características da mobilização social, que assumiu a forma de uma cruzada moral, representada na luta do bem (o "nós") contra o mal ("eles"). Se no plano eleitoral, o antipetismo pode apontar para o fortalecimento dos partidos de centro-direita dispostos a defender as regras do jogo democrático, no plano sócio-político, o antipetismo tem natureza intrinsecamente antidemocrática.

Como dito anteriormente, o antipetismo (seja como fenômeno sociopolítico, seja como fenômeno político-eleitoral) tem nos escândalos de corrupção sua matéria-prima, pelo menos desde 2005. Mas, é a partir de 2015, quando as ações da justiça brasileira se confundem com os interesses políticos da base social antipetista, que foi possível não só vincular seletivamente o PT à corrupção, como definir esta última como o grande problema nacional. Um bom exemplo foi a contestação simbólica do slogan do governo de Dilma Rousseff "País rico é país sem pobreza", que fora redefinido nas faixas e cartazes apresentados nas manifestações como "País rico é país sem corrupção". O êxito dos oposicionistas em reconstruírem o terreno simbólico do confronto fica evidente na mudança da opinião pública: pesquisa divulgada pelo Instituto Datafolha, em novembro de 2015, aponta que, pela primeira vez, a corrupção foi eleita como principal problema pelos brasileiros (para 34\% dos entrevistados), deixando para trás temas tradicionais, como saúde (16\% das menções espontâneas), desemprego (8\%) e educação (8\%) (Datafolha 2015b).

No discurso das lideranças pró-impeachment é comum a narrativa segundo a qual o Estado fora assaltado por uma quadrilha composta por sindicalistas e movimentos sociais, com o objetivo de enriquecimento pessoal ilícito e/ou perpetuação de um projeto de poder de natureza populista. Ao ex-presidente Lula se atribui o papel de "chefe da quadrilha". O slogan "CorruPTos", muito presente nos cartazes exibidos nos protestos, sintetiza com perfeição o humor das ruas.

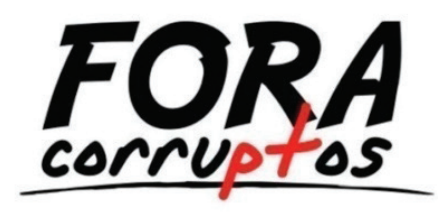


A associação da corrupção ao PT ofereceu um poderoso enquadramento simbólico para o conflito: o problema do Brasil é a corrupção, a causa da corrupção são os governos do PT e a superação do problema é o "Fora PT", "Fora Lula" e "Fora Dilma" (Tatagiba, Trindade e Teixeira 2015). A nova direita foi capaz de inovar sobre as bases da tradição, afinal, no caso brasileiro o combate à corrupção tem sido um dos principais frames dos ciclos de confronto no período democrático, utilizado como recurso de mobilização tanto à direita quanto à esquerda (Tatagiba 1998, Tatagiba 2014, Tatagiba, Trindade e Teixeira 2015).

As investigações da Lava Jato e a sincronização das arenas institucionais e extra-institucionais

$\mathrm{O}$ argumento central nesse item é que a ação das autoridades judiciais - principalmente Polícia Federal, Ministério Público e Supremo Tribunal Federal - foi decisiva para o sucesso do movimento oposicionista, a partir da megaoperação voltada a investigar desvios na maior estatal brasileira, a petrolífera Petrobras, intitulada "Operação Lava Jato". A Operação Lava Jato, deflagrada em março de 2014, implicou grandes empreiteiras, políticos eleitos de várias agremiações partidárias, operadores financeiros e altos cargos da burocracia pública, nos diversos níveis da federação. Nesses 4 anos de operação, instalou-se mais de 2 mil procedimentos, inúmeras prisões preventivas, conduções coercitivas e farto uso das delações premiadas. A investigação atingiu seus dois grandes objetivos: em agosto de 2016, consumou-se o impeachment de Dilma Rousseff, e em abril de 2018, a prisão do ex-presidente Lula.

A politização da justiça no Brasil tem sido objeto de estudo e alvo de denúncia de inúmeros pesquisadores e ativistas, principalmente a partir de 2015, quando os recursos utilizados na investigação (com destaque para o dispositivo da delação premiada) passam a ferir princípios básicos do Estado Democrático de Direito. Os estudos também apontam para os prejuízos desse ativismo judiciário sem precedentes sobre o sistema político brasileiro, que acabou por produzir uma criminalização de toda a atividade política, lançando o país na mais grave crise política e institucional de sua história (Avritzer 2016, Avritzer e Marona 2017, Santos 2017). Não vamos nos aprofundar aqui nesse debate. Neste item, interessa-nos compreender como essa ação política e seletiva da Justiça brasileira turbinou os protestos, ao mesmo tempo em que encontrou nela base importante de legitimação. Contar com aliados na esfera do judiciário foi um recurso decisivo de que puderam dispor os oposicionistas na construção de sua exitosa campanha. A breve cronologia dos eventos explicita esses nexos 
entre as esferas institucionais e contestatória e mostra como a interferência do Judiciário foi decisiva para modelar o resultado final do conflito.

A campanha pelo impeachment. Cronologia dos eventos

17/03/2014 Deflagrada $1^{\text {a }}$ fase da Operação Lava Jato, da Polícia Federal

22/03/2014 Marcha da Família com Deus contra o governo do PT

14/05/2014 Instalada a CPI da Petrobrás no Senado

21/10/2014 Em delação premiada, denunciado envolve Lula e Rousseff no escândalo da Petrobras

25/10/2014 Ato em São Paulo simula o enterro de Dilma Rousseff

26/10/2014 Dilma Rousseff é reeleita

26/10/2014 Aécio Neves (PSDB) convoca manifestação contra o resultado da eleição

01/11/2014 Protestos em 4 capitais pedem impeachment de Rousseff

o6/12/2014 Novo protesto contra Rousseff em São Paulo

18/12/2014 PSD в ingressa com pedido de anulação da eleição

01/01/2015 Dilma Rousseff toma posse e inicia seu segundo mandato

15/03/2015 Primeira grande manifestação pelo impeachment

16/03/2015 Tem início a $10^{\text {a }}$ fase da Operação Lava Jato

12/04/2015 Segunda grande manifestação pelo impeachment

15/04/2015 $12^{\mathrm{a}}$ fase da Operação Lava Jato prende o ex-tesoureiro do PT

17/07/2015 Presidente da Câmara rompe com o governo e anuncia que é da oposição

03/o8/2015 $17^{\mathrm{a}}$ fase da Operação prende o ex-ministro José Dirceu, Ministro do Governo Lula

o6/o8/2015 Várias capitais registram panelaço durante programa eleitoral do PT

16/o8/2015 Terceira grande manifestação pelo impeachment

o6/10/2015 Tribunal Superior Eleitoral reabre ação para impugnar chapa Dilma/ Temer

07/10/2015 Tribunal de Contas da União recomenda reprovação das contas do governo por "pedaladas fiscais"

21/10/2015 Parlamentares da oposição entregam pedido de impeachment

25/11/2015 Líder do Governo no Senado é preso por obstruir as investigações da Lava Jato

02/12/2015 Presidente da Câmara autoriza abertura do processo de impeachment

13/12/2015 Quarta grande manifestação pelo impeachment

03/02/2016 Sete capitais registram panelaço contra pronunciamento da Presidenta Rousseff. 
A campanha pelo impeachment. Cronologia dos eventos (cont.)

23/02/2016 Publicitário que trabalhou nas campanhas de Lula e Rousseff é preso

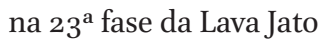

04/03/2016 Lula é alvo de prisão coercitiva para prestar esclarecimentos

13/03/2016 Quinto e maior protesto pelo impeachment e pela prisão de Lula.

16/03/2016 Lula é anunciado Ministro Chefe da Casa Civil

16/03/2016 Juiz Sérgio Moro quebra sigilo e divulga áudio de conversa entre Lula e Rousseff

16/03/2016 Protestos em 16 capitais contra a nomeação de Lula para a Casa Civil

17/03/2016 "Occupy Paulista", contra nomeação de Lula

18/03/2016 Supremo Tribunal Federal suspende nomeação de Lula para a casa Civil

17/04/2016 Com 367 votos a favor, pedido de impeachment é aprovado na Câmara

12/05/2016 Senado aprova abertura do processo de impeachment e Rousseff é afastada da Presidência

31/o8/2016 Dilma Rousseff é afastada definitivamente da Presidência da República

Em 17 de março de 2014 foi deflagrada a Operação Lava Jato, tendo como objetivo investigar redes operadas por doleiros que praticavam crimes financeiros com dinheiro público. Com a prisão do doleiro Alberto Youssef, o desvio de recursos da Petrobras para pagamento de propina tornou-se o principal alvo das investigações. Nascia ali o "escândalo do Petrolão". Três dias antes do segundo turno da eleição presidencial, Youssef declarou em delação premiada que Lula e Rousseff tinham conhecimento da rede de corrupção montada na Petrobras. A denúncia foi capa da edição de domingo de uma revista de circulação nacional que mostrava a foto dos dois presidentes seguida da frase "Eles sabiam de tudo" (Revista Veja 2014). Desde então, as investigações do "Petrolão" passaram a mirar o Partido dos Trabalhadores e a receber ampla cobertura da imprensa. Dilma Rousseff foi reeleita com uma diferença de $3 \%$ dos votos válidos. Horas depois, como já mencionado, o candidato derrotado, Aécio Neves, anunciou que iria liderar a campanha pela sua destituição, colocando em suspeição a legitimidade do pleito.

Em janeiro de 2015, Dilma Rousseff iniciou seu segundo mandato sob fogo cruzado, com um cenário que combinava crise política e crise econômica. Visando reagir à crise e responder as exigências do mercado, um mês após ser reeleita, Rousseff contrariou promessas de campanha e deu início a um programa de ajuste fiscal, nos moldes defendidos pelo candidato derrotado, dando fim ao "ensaio neodesenvolvimentista" que marcara o seu primeiro mandato (Singer 2016). O aceno ao mercado não surtiu os efeitos esperados e 


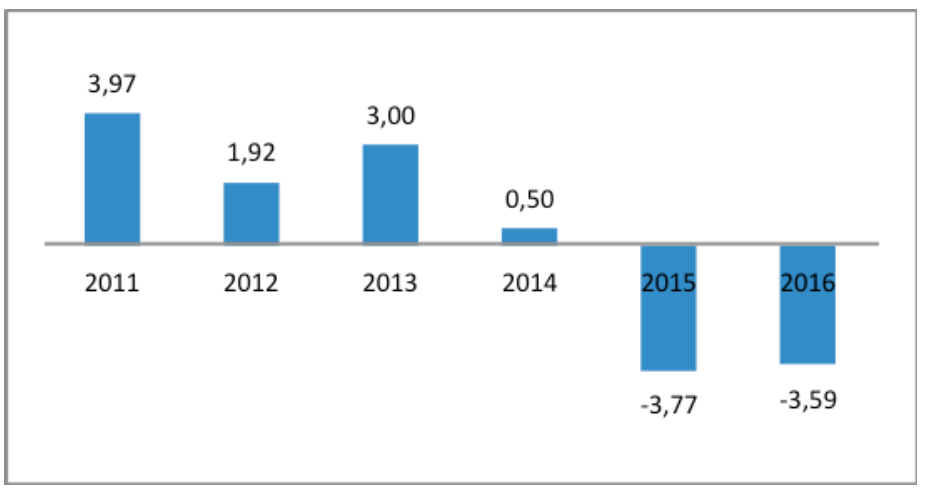

GRÁfiCO 2 Variação (em volume) do Produto Interno Bruto (\%). FONTE: INSTITUTO BRASILEIRO DE GEOGRAFIA E ESTATÍSTICA, 2016.

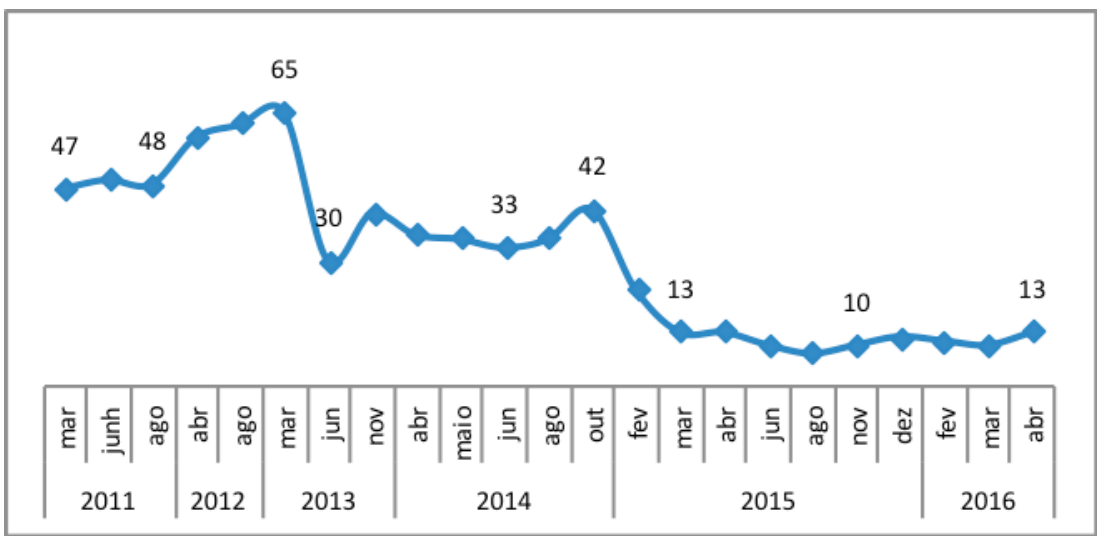

GRÁfico 3 Percentual dos que consideram o governo Rousseff ótimo/bom. FONTE: INSTITUTO DATAFOLHA, 2013 E 2016.

agravou as relações de Rousseff com sua base aliada, que acusou a presidente de estelionato eleitoral. A queda nos indicadores econômicos e de popularidade do governo abriram oportunidades inéditas para o avanço dos oposicionistas nas ruas.

Ainda no começo do segundo mandato, as relações com o Congresso Nacional se deterioram com a eleição de Eduardo Cunha para a Presidência da Câmara dos Deputados, que venceu o candidato indicado pelo Palácio do Planalto. No auge das mobilizações e sob o cerco da Lava Jato, Cunha rompeu com o Governo, aproximou-se dos oposicionistas e abriu caminho para o trâmite do processo de impeachment no Legislativo. 
A deterioração da imagem da presidente junto à opinião pública ficou evidente com as grandes mobilizações, já no começo de 2015. O primeiro sinal disso foram os "panelaços" realizados durante pronunciamento da Presidenta em homenagem ao dia Internacional da Mulher, em 8 de março de 2015. Ao longo dos 15 minutos de fala da Presidenta em rede nacional, "panelaços" foram ouvidos em áreas nobres de 12 capitais do país. Os protestos foram convocados em redes sociais e em aplicativos de celular e tiveram ampla repercussão nas mídias e nos telejornais.

Entre março e agosto de 2015, houve três grandes mobilizações pelo impeachment. Nos protestos, era comum a presença de cartazes em defesa da Polícia Federal, Ministério Público e do juiz Sérgio Moro, responsável pelas investigações, e que foi alçado à posição de herói nacional. O caso do boneco "Pixuleco" é um exemplo anedótico dessas interconexões. Em 15 de abril de 2015, o extesoureiro do PT, João Vaccari Neto foi preso na $12^{\text {a }}$ fase da Lava Jato, suspeito de receber as propinas que recolhia das empresas que tinham contratos com a Petrobras. Segundo depoimentos feitos em acordo de delação premiada, "Pixuleco" era a forma como Vaccari se referia à propina (Lima 2015, Uribe 2015). Desde então, "Pixuleco" passou a significar propina nos documentos da Operação Lava Jato. Em junho de 2015, um empresário resolveu criar um símbolo para a campanha do impeachment: um boneco inflável gigante do Presidente Lula, com 12 metros de altura, vestido de presidiário e com uma bola de ferro presa aos pés onde se lia "Operação Lava Jato". Contudo, faltava encontrar um nome para o boneco. A resposta veio com a $17^{\mathrm{a}}$ Fase da Operação Lava, intitulada "Operação Pixuleco", lançada em 3 de agosto. Com o objetivo de dar visibilidade à Operação e demonstrar o apoio à Lava Jato, o boneco foi batizado de "Pixuleco" e desde então passou a fazer aparições públicas nos protestos pelo impeachment, em diversas cidades brasileiras, onde réplicas do boneco em tamanho menor também podiam ser compradas a preços populares (Kaz 2015).

O êxito das mobilizações realizadas no primeiro semestre em 2015, impulsionou novas investidas no plano institucional visando a interrupção do mandato da Presidenta: no dia 6 de novembro o Tribunal Superior Eleitoral (TSE) reabriu ação para impugnar a chapa Dilma/Temer; no dia seguinte, o Tribunal de Contas da União (TCU) recomendou a reprovação das contas do governo por "pedaladas fiscais", e cerca de duas semanas depois juristas consagrados entregaram pedido de impeachment ao presidente da Câmara dos Deputados.

O ano de 2016 começou com novos "panelaços" e com a prisão do publicitário que trabalhou nas campanhas de Dilma Rousseff e do ex-presidente Lula. Segundo os investigadores, o publicitário teria sido pago por serviços prestados 
ao PT com recursos desviados da Petrobras. Com essa prisão as investigações se aproximavam ainda mais do ex-presidente Lula e do PT, ampliando a extensão da crise para além da interrupção do mandato da presidente. Na expressiva manifestação de 13 de março de 2016 um cartaz recupera com precisão o que parecia estar em jogo na conjuntura: "Agora a gente tira a Dilma. Depois a gente dobra a aposta e prende o Lula".

Essa direção fica mais clara na $24^{\mathrm{a}}$ fase da Operação Lava Jato que passou a investigar a relação de Lula e seus familiares com empreiteiras denunciadas pela Lava Jato. Como parte da operação, Lula foi conduzido coercitivamente para prestar esclarecimentos ao juiz Sérgio Moro, na sede da Polícia Federal, em Curitiba, no dia 04 de março. A ação contra o ex-presidente elevou em muito a temperatura do conflito, com a realização de grandes protestos contra e a favor do impeachment. Cerca de uma semana depois da condução coercitiva de Lula, houve o quinto e maior protesto antigoverno. Segundo o Instituto Datafolha, esse foi o maior evento de protesto na cidade de São Paulo que se tem registro (Folha de São Paulo 2016). Nas ruas, as palavras de ordem exigiam o impeachment de Rousseff, a prisão de Lula e a defesa da Lava Jato e do Juiz Sérgio Moro.

Três dias depois, em 16 de março, Rousseff nomeou o ex-presidente Lula como Ministro Chefe da Casa Civil, como um último esforço de aplacar a crise e rearticular a base aliada no Congresso. Horas depois, o Juiz Sérgio Moro, em manobra inédita, retirou o sigilo de interceptações telefônicas do ex-presidente Lula, divulgando uma conversa gravada entre ele e a Presidenta Rousseff. No áudio, a Presidenta informa que está enviando para Lula o termo de posse como ministro e que ele só deveria usar o documento "em caso de necessidade". Segundo a interpretação da oposição, o documento teria como objetivo livrar Lula de uma possível ação judicial. À noite, as âncoras do telejornal da Rede Globo reproduziram sob a forma de uma encenação o diálogo entre Lula e Rousseff. Foi como um rastilho de pólvora que se espalhou sob a forma de protestos em várias cidades brasileiras, terminando com o "Occupy paulista" - uma ocupação dos militantes pelo impeachment, em frente ao prédio da FIESP, na Avenida Paulista, principal cenário político e econômico do país - para exigir a prisão de Lula. No dia 18 de março, o Supremo Tribunal Federal suspendeu a nomeação do expresidente acatando a ação apresentada pelo PSDB e PPS, abortando uma possível solução à crise de governabilidade.

A divulgação dos áudios e, logo na sequência, a decisão do STF evidenciaram a disposição do judiciário brasileiro de agir como ator político interferindo fortemente na natureza da disputa. Como sugere Nobre, "A partir daquele momento, não existe mais neutralidade política da Lava Jato. Aquele ato mudou 
a história do país de uma tal maneira que a Lava Jato vai, progressivamente, se identificando como uma força antiPT" (Nobre 2018).

Em 17 de abril, a Câmara dos Deputados aprovou o impeachment por 367 votos favoráveis, 137 contrários, 7 abstenções e duas ausências. O processo seguiu então para o Senado, que acolheu o pedido aprovando o afastamento temporário de Rousseff por 180 dias, com 55 votos a favor e 22 contra. Em 31 de agosto de 2016, o Plenário do Senado votou o tema e aprovou o impedimento por 61 votos favoráveis e 20 contrários. Dilma Rousseff perdeu o seu mandato sob a acusação de haver cometido crime de responsabilidade fiscal, as "pedaladas", afastando-se definitivamente da Presidência.

No mesmo dia os manifestantes comemoraram nas ruas a vitoriosa campanha. Em São Paulo, foram 220 mil pessoas na Avenida Paulista, segundo o Instituto Datafolha. Mas, os manifestantes pró-impeachment pouco ou nenhum poder teriam para construir o futuro governo. Segundo as pesquisas de opinião realizadas nos protestos, os manifestantes esperavam votar novamente para escolher o presidente (Bachtöld 2016). Mas, quem assumiu foi o vicepresidente, Michel Temer que, em 3 de maio de 2016, já havia sido condenado pelo Tribunal Eleitoral Regional de São Paulo por doação irregular de campanha e tornado inelegível por oito anos.

\section{$4 \quad$ Considerações finais}

Desde os protestos de Junho de 2013, o Brasil vive uma combinação entre crise política e crise econômica que desaguou, a partir do final de 2014, em uma das mais graves crises institucionais de sua história. $O$ ponto de inflexão foi a campanha pelo impeachment de Dilma Rousseff, levada a termo entre outubro de 2014 e agosto de 2016. A grande novidade dessa campanha foi a emergência das novas direitas nas ruas. Esse texto, que tem sentido exploratório, buscou lançar luz sobre essa novidade, buscando compreender as condições para o sucesso das mobilizações que, em exatos 22 meses, destituíram uma presidenta legitimamente eleita.

Como busquei evidenciar, os protestos foram resultado da laboriosa construção de um processo de identificação que teve no antipetismo seu elemento catalizador. O ódio ao PT é um fenômeno sociopolítico que funcionou como gatilho emocional para os protestos. $\mathrm{O}$ antipetismo ofereceu a energia moral para o engajamento ativo e os marcos simbólicos para o enquadramento do conflito, em um contexto de intensa polarização política. Mais do que destituir Dilma Rousseff, o que estava em jogo nas manifestações era "extirpar o mal da política brasileira", personificado no PT e suas lideranças. 
O núcleo do antipetismo reside numa bem-sucedida articulação entre a corrupção e o modo petista de governar, possível a partir da Operação Lava Jato, iniciada em 2014. Os escândalos de corrupção são a matéria-prima de que se nutre o antipetismo, e a atuação seletiva da Polícia Federal e do Ministério Público permitiram uma forte associação na opinião pública entre a luta contra a corrupção - um dos principais master frames dos ciclos de mobilização no Brasil (Tatagiba 2014) - e o modo petista de governar, dando forte sustentação aos processos de mobilização em curso. As prisões espetaculares de dirigentes petistas, o vazamento de informações, a divulgação do conteúdo das delações premiadas em momentos críticos foram ações que permitiram manter o estado de mobilização e a disposição para o enfrentamento. Da mesma forma, o "clamor das ruas" conferiu legitimidade às ações do juiz Sérgio Moro, responsável pelas investigações, apesar dos flagrantes abusos cometidos no processo na produção das provas e julgamento. O sucesso da campanha pelo impeachment resulta dessa sincronização das arenas institucionais e extra institucionais, que permitiu superar os diferentes obstáculos colocados para o avanço do impeachment como encaminhamento da crise política.

\section{Referências bibliográficas}

Alonso, A., \& Mische, A., 2015, "June demonstrations in Brazil: repertoires of contention and government's response to protest", consultado em 26 de fevereiro 2016, htps:// www.academia.edu/11309520/June_demonstrations_in_Brazil_repertoires_of_ contention_and_government_s_response_to_protest.

Amaral, O. 2010, "As transformações na organização interna do Partido dos Trabalhadores", Tese de Doutorado, Programa de Pós-Graduação em Ciência Política, Unicamp, Campinas.

Antunes, R. 2013, "As rebeliões de junho de 2013", OSAL Observatorio Social de América Latina, XIV (34): 37-49.

Avrizter, L. 2016, Impasses da democracia no Brasil. Rio de Janeiro, Editora Civilização Brasileira.

Avritzer, L. \& Marona, M. 2017, "A Tensão entre Soberania e Instituições de Controle na Democracia Brasileira", Dados, 60 (2): 359-393.

Bringel, B. 2017, "Crisis política y polarización en Brasil: de las protestas de 2013 al golpe de 2016", in B. Bringel \& G. Pleyers eds., Protesta e indignación global: Los movimientos sociales en el nuevo orden mundial, Ciudad Autónoma de Buenos Aires, CLACSO/Rio de Janeiro, FAPERJ. 
Datafolha, 2015a, "Manifestação na Avenida Paulista 15/03/2015" consultado em 11/12/ 2017, http://media.folha.uol.com.br/datafolha/2015/03/17/manifestacao-15-03.pdf.

Datafolha, 2015b, "Manifestação na Avenida Paulista 16/08/2015" consultado em 11/12/2017, consultado em 11/12/2017, http://media.folha.uol.com.br/datafolha/ 2015/08/17/manifestacao-16-08.pdf.

Dias, T. 2017, "É uma batalha de narrativas". Os enquadramentos de ação coletiva em torno do impeachment de Dilma Rousseff no Facebook, dissertação de mestrado em Ciência Política, Instituto de Ciência Política, Universidade de Brasília.

Doimo, A. M. 1995, A vez e a voz do popular. Movimentos sociais e participação política no Brasil pós-7o, Rio de Janeiro, Relume-Dumará/An pocs.

Dreifuss, A. 1981, 1964: A conquista do Estado. Ação política, poder e golpe de classe, Petrópolis, Vozes.

Fundação Perseu Abramo, 2016, "Projeto Manifestações março comparativo 13 e18 e 2015 e 2016 comparativo, Núcleo de Estudos de Opinião Pública - março 2016” consultado em 23/o8/2017, https://fpabramo.org.br/publicacoes/publicacao/manifestacoesmarco-comparativo-201520162017/.

Gobbi, D. 2016, Identidade em ambiente virtual. Uma análise da Rede Estudantes Pela Liberdade, Dissertação de Mestrado, Instituto de Política, Universidade de Brasília. Index e Amostra 2015, "Perfil dos manifestantes Porto Alegre 15/03/2015", consultado em 10/10/2017, http://zh.clicrbs.com.br/rs/noticias/noticia/2015/03/institutos-depesquisa-fazem-levantamentos-sobre-o-perfil-dos-manifestantes-em-portoalegre-4719348.html.

Judensnaider, E. et al. 2013, Vinte centavos. A luta contra o aumento, São Paulo, Veneta.

Keck, M. 1992, The Workers' Party and democratization in Brazil, New Haven, Yale University Press.

Martins Jr., J. P. 2009, "Modelo sociológico de decisão de voto presidencial no Brasil 1994-2006", Revista Debates, 3 (2): 68-96.

Mcadam, D. \& Tarrow, S. 2011[2010], "Movimentos sociais e eleições: por uma compreensão mais ampla do contexto político da contestação", Sociologias 13 (28): 18-51.

McAdam, D., Tarrow, S. \& Tilly, C. 2001, Dynamics of Contention, Cambridge/New York, Cambridge University Press.

Meneguello, R. 1989, PT. A formação de um partido 1979-1982, Rio de Janeiro, Paz e Terra.

Ortelado, P., Solano, E. \& Nader, L. 2015, "Pesquisa manifestação política 16 de agosto de 2015”, consultado em 2/07/2017, https://gpopai.usp.br/pesquisa/160815/.

Paiva, D., Krause, S. \& Lameirão, A. P. 2016, “O eleitor antipetista: partidarismo e avaliação retrospectiva” Opinião Pública, 22 (3): 638-674.

Pierucci, A. F. 1987, "As bases da nova direita", Novos Estudos Cebrap, 19: 26-45.

Ribeiro, E., Carreirao, Y. \& Borba, J. 2016, "Sentimentos partidários e antipetismo: condicionantes e covariantes”, Opinião Pública, 22, (3): 603-637. 
Rubim, L. \& Argolo, F. eds. 2018, O golpe na perspectiva de gênero, Salvador, Edufab.

Sader, E. 1988, Quando novos personagens entraram em cena, Rio de Janeiro, Paz e Terra. Samuels, D. \& Zucco, C. 2015. "Partisans, anti-partisans and voting behavior in Brazil", Paper apresentado no Encontro da American Political Science Association (APSA), San Francisco.

Santos, W. G. 2017, Democracia impedida. O Brasil no século XXI, São Paulo, FGv Editora. Singer, A. 2013, "Brasil, Junho de 2013 - Classes e ideologias cruzadas", Novos Estudos, 97: $23-40$.

Singer, A. 2012, Os sentidos do lulismo. Reforma gradual e pacto conservador, São Paulo, Companhia das Letras.

Solano, E. \& Ortellado, P. 2015, "Pesquisa com os participantes da manifestação do dia 12 de abril de 2015 sobre confiança no sistema político e fontes de informação", consultado em 2/07/2017, https://gpopai.usp.br/pesquisa/120415/.

Solano, E., Ribeiro, M. \& Ortellado, P. 2016, "Pesquisa na manifestação contra o impeachment do dia 31 de março de 2016", consultado em 20/03/2017, https://gpopai .usp.br/pesquisa/310316/.

Tatagiba, L. 1998, Dos significados da "ética na política". Articulação e discurso no contexto pró-impeachment, dissertação de mestrado em Ciência Política, Instituto de Filosofia e Ciências Humanas, Unicamp.

Tatagiba, L. 2014, "1984, 1992 e 2013. Sobre ciclos de protestos e democracia no Brasil", Política e Sociedade, 13 (28): 35-62.

Tatagiba, L., Trindade, T. \& Teixeira, A.C. 2015, "Protestos à direita no Brasil (1997-2015)", in S.V. e Cruz, A. Kaysel, \& G. Codas, Gustavo eds. Direita, volver! O retorno da direita e o ciclo político brasileiro, São Paulo, Fundação Perseu Abramo: 197-212.

Tatagiba, L. e Galvão, A. 2018. Os protestos no Brasil em tempos de crise (2011-2016), São Paulo, mimeo.

Telles, H. 2015, "Perfil ideológico e atitudes políticas dos manifestantes 12/04/2015, Belo Horizonte", consultado em 18/o1/2018, http://opiniaopublica.ufmg.br/site/pesquisas/ perfil-ideologico-e-atitudes-politicas-dos-manifestantes-de-12-de-abril-belo -horizonte;

Tilly, C. 2006, Regimes and repertoires, Chicago, University of Chicago Press.

\section{Artigo de imprensa}

Bachtöld, F. 2016, "Manifestantes pró e contra Dilma rejeitam Temer, aponta Datafolha", Folha de São Paulo, consultado em 4/o6/2018, http://www1.folha.uol.com.br/ poder/2016/04/1762217-manifestantes-pro-e-contra-dilma-rejeitam-temer-aponta -datafolha.shtml

Calgaro, F. 2015, "Grupo de maçons protesta na Câmara contra corrupção e o governo do PT", globo.com, consultado em 4/o6/2018, http://g1.globo.com/politica/noticia/ 2016/o2/grupo-de-macons-protesta-na-camara-contra-corrupcao-e-o-pt.html 
Folha de São Paulo 2016, "Protesto na av. Paulista é o maior ato político já registrado em São Paulo", Folha de São Paulo, consultado em 4/o6/2018, http://wwwı.folha.uol .com.br/poder/2016/03/1749528-protesto-na-av-paulista-e-o-maior-ato-politicoja-registrado-em-sao-paulo.shtml

Kaz, R. 2015, "Na estrada com pixuleco", Folha de São Paulo, consultado em 4/o6/2018, http://piaui.folha.uol.com.br/materia/na-estrada-com-pixuleco/

Lima, D. 2015, "Gíria da malandragem, pixuleco agora vira sinônimo de propina", Folha de São Paulo, consultado em 4/06/2018, https://www1.folha.uol.com.br/ poder/2015/o6/1649031-giria-da-malandragem-pixuleco-agora-vira-sinonimo-depropina.shtml

Nobre, M. 2018. "Com o campo progressista fragmentado, a centro-direita leva de lavada durante anos". El País, consultado em 11/04/2018, https://brasil.elpais.com/ brasil/2018/04/o8/politica/1523210065_818206.htm

Uribe G. 2015, "Boneco inflável de Lula fica famoso e vai viajar pelo país", Folha de São Paulo, consultado em 4/06/2018, https://www1.folha.uol.com.br/fsp/poder/ 230007-boneco-inflavel-de-lula-fica-famoso-e-vai-viajar-pelo-pais.shtml

Viegas, N. 2015, "Maçons querem impeachment", globo.com, consultado em 4/o6/2018, http://epoca.globo.com/tempo/expresso/noticia/2015/og/macons-queremimpeachment.html

$\mathrm{O}$ autor agradece as contribuições dos pareceristas à primeira versão desse texto. A pesquisa conta com o apoio financeiro do Conselho Nacional de Desenvolvimento Científico e Tecnológico (CNPq). 